\title{
A METHOD OF RESEARCH OF THE CAUSES AND EFFECTS OF PROBLEMS WITH LOW ALLOY STEEL PRODUCTS
}

\author{
Dominika SIWIEC ${ }^{1}$, Andrzej PACANA² \\ Rzeszow University of Technology, Rzeszow, Poland, EU, \\ 1‥siwiec@prz.edu.pl, ${ }^{2}$ app @prz.edu.pl
}

https://doi.org/10.37904/metal.2021.4085

\begin{abstract}
A popular way in applying to identify incompatibilities of a product are non-destructive testing (NDT). However, this research is not allowed to identify the causes of incompatibilities. It concerns solving the decision problems, in which the causes and effects of these incompatibilities are determined. Therefore, the aim of the article is to propose the method to solve causes and effects problems as a part of determining the main cause of problem. This includes generating possible causes of the problem and their careful analysis in order to determine the main cause of this problem. This method is a combination of techniques, i.e. brainstorm (BM), Ishikawa diagram, and DEMATEL method. The method was designed in five main stages, i.e.: determining the aim, selecting the team of experts, determining the causes of problem, identifying the main cause of problem, determining the improvement actions, and determining the improvement actions. The test of the method for frequent incompatibility with non-metallic inclusions on product from AMS6415 steel was conducted. This incompatibility was detected by NDT research (magnetic powder method) in the Podkarpacie enterprise. After using the proposed method for this problem, it was shown that the main causes of its occurrence were errors in plastic working and untrained workers. The originality of the article is a new combination of methods for an analysis of a complex cause-and-effect problems with non-destructive testing.
\end{abstract}

Keywords: AMS6415 steel, non-metallic inclusions, mechanical engineering, DEMATEL method, decision support

\section{INTRODUCTION}

Improving the product quality is the basis of developing enterprises, which activities are targeted to achieve the customers' satisfaction [1,2]. For this purpose, various actions are taken, e.g. the control of a quality product, or the prevention to the occurrence of the incompatibility $[2,3]$. These mentioned controls are mainly realized by an effective non-destructive testing (NDT), which allow to control the quality of the product without its destruction [3]. Their application allows to identify the incompatibility of the product, however it does not allow to determine the causes of its occurrence. Therefore, the enterprises search for other methods, which in combination with NDT research will allow for the complex cause and effect analysis. The review of the literature has shown that for this purpose mainly the brainstorm (BM) [4,5] and Ishikawa diagram (cause and effect) $[3,6,7,8]$ were used. The mentioned BM was used, for example, to define the largest possible number of ideas, e.g. the causes of the problem [4,5]. In turn, the Ishikawa diagram was used e.g. for identifying and grouping the causes of the problem $[6,7,8]$. Also, this diagram was used for visualizing the mutual correlation between the cause and the effect [3]. Additionally, the DEMATEL method, intended for this purpose, was used for the cause and effect analyses $[9,10,11,12,13]$. It is a method for making trial and evaluation decisions, which has been applied to analyse the complex cause and effect connections [13]. The DEMATEL method allows the research of the relationships and correlations in elements of a system, and also it determines so-called critical elements in the system as a part of connections diagram [10,11,13]. For example, in Ref. [13] the literature review of this method was shown. However, it was concluded that this method was not used in a combination 
with mentioned techniques of the quality management. For this reason, it was assumed as adequate to propose a new method of combined techniques to research the connections of causes and effects, in the context to determine the main causes of the problem. The test of method was conducted on the example of non-metallic inclusions of a product from ASM6415 steel, which was made by non-destructive testing (magnetic-powder method).

\section{METHOD}

The proposed method is a combination of techniques, i.e. brainstorm (BM), Ishikawa diagram (cause and effect) and DEMATEL method. The aim of the method is to solve the cause and effect problem as a part of determining the main cause of the problem. This includes generating possible causes of the problem and their careful analysis in order to determine the main cause of this problem. The selection of these techniques resulted from their application to determine causes and effects of the problem (brainstorm and Ishikawa diagram) $[3,4,5,6,7,8]$, and the effective assessments of connections of causes and effects (DEMATEL method) $[4,9,10,11,12,13]$. However, previous techniques were not combination as a single, coherent method. The proposed method was designed in five main stages (Figure 1).

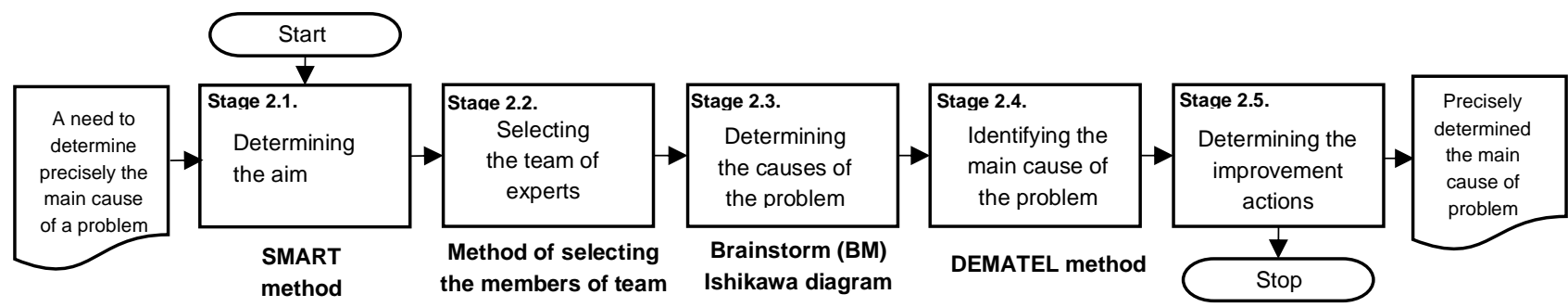

Figure $1 \mathrm{An}$ algorithm of combination method to solve the cause and effect problems

The short characteristic of stages of the proposed method is shown in the next part of article.

\subsection{Determining the aim}

The first stage is determining the aim. The aim should refer to solving the cause and effect problem and identifying precisely the main cause of the problem. As a part of determination of the aim, the SMART method can be used [14].

\subsection{Selecting the team of experts}

The second stage is selecting the team of experts. The team is responsible for identifying the main cause of the problem, so it determines and makes an assessment in the cause of the problem as a part of cause and effect analysis. For this reason, the members of a team should have competencies and knowledge about the problem. The example of selecting the experts to a team is shown e.g. in $[15,16]$.

\subsection{Determining the causes of the problem}

The third stage is determining the causes of the problem. This stage is realized by the team of experts. Initially, the brainstorm (BM) is made to generate the causes of the problem. The method of BM is shown e.g. in $[4,5]$. All causes of the problem should be noted in a visible place to the team, e.g. blackboard. Then, these causes can be grouped according to some categories. These categories should be selected because of the character of causes of the problem. In the proposed method, the Ishikawa categories $(5 \mathrm{M}+\mathrm{E})$ can be used, i.e.: man, method, machine, material, management and environment [3]. The group of the cause can be visualized on the cause and effect diagram, as a part of standardized analyse by DEMATEL method, which is shown in the next stage of the method. 


\subsection{Identifying the main cause of problem}

The fourth stage is identifying the main cause of problem. This stage is realized by the team of experts applying the DEMATEL method. Initially, the causes from the cause and effect diagram (stage 2.3.) should be evaluated. Hence, the causes of problem are noted in rows and columns of $A$ matrix. Then, the direct mutual influence of these causes in scale 0-4 is evaluated, where 0 - no influence, 1 - low influence, 2 - average influence, 3 - high influence, and 4 - very high influence. The assessment of direct mutual influence of causes is realized in A matrix (1) $[9,10,11,12,13]$ :

$$
A_{i}=\left[\begin{array}{ccccc}
0 & a_{12}^{*} & a_{13}^{*} & \ldots & a_{1 n}^{*} \\
a_{21}^{*} & 0 & a_{23}^{*} & \ldots & a_{2 n}^{*} \\
a_{31}^{*} & a_{32}^{*} & 0 & \cdots & a_{3 n}^{*} \\
\vdots & \vdots & \vdots & \ddots & a_{i n}^{*} \\
a_{n 1}^{*} & a_{n 2}^{*} & a_{n 3}^{*} & \cdots & 0
\end{array}\right]
$$

where: $\mathrm{i}$ - assessment of direct and mutual influence of causes.

Then, the structure of the total impact of these causes is determined. For this purpose, it is necessary to normalize A matrix (2). Next, in T matrix is determined as the entire and mutual influence of these causes (3) $[9,10,11,12,13]$ :

$$
\begin{aligned}
k & =\frac{1}{\max _{1 \leq i \leq n} \sum_{j=1}^{n} a_{i j}}, \quad Y=k \cdot A \\
T & =Y(I-Y)^{-1}
\end{aligned}
$$

where: $i, j=1,2, \ldots, n, A$ - the matrix of a direct influence of causes, $Y$ - normalized matrix, I-identity matrix. Then, in order to determine the degree of mutual causes, the sum of assessments in rows and columns of $T$ matrix should be calculated, and also the average assessments of all causes in T matrix $(4)[9,10,11,12,13]$ :

$$
R_{i}=\left[\sum_{j=1}^{n} t_{i j}\right]_{n \times 1}=\left[t_{i}\right]_{n \times 1}, \quad C_{j}=\left[\sum_{i=1}^{n} t_{i j}\right]_{1 \times n}=\left[t_{j}\right]_{n \times 1}, \quad \alpha=\frac{\sum_{i=1}^{n} \sum_{j=1}^{n}\left[t_{i j}\right]}{N}
$$

where: $\mathrm{i}, \mathrm{j}=1,2, \ldots, \mathrm{n}, \mathrm{R}$ - row, $\mathrm{C}$ - column, $\mathrm{t}$ - value of T matrix, $\mathrm{N}$ - number of all causes.

As a result, the values from the $T$ matrix which are above the average value $(\alpha)$ indicate an important and mutual influence on the occurrence of the problem. After removing the values below the mean value $(\alpha)$, it is necessary to create a diagram of the impact on the causes of the problem $[9,10,11,12,13]$. As part of the DEMATEL diagram it is possible to visualize the mutual influence of causes, but also determine the main cause, i.e. with the biggest influence on the occurrence of the problem.

\subsection{Determining the improvement actions}

The fifth stage is determining the improvement actions. This stage is realized by the team of experts. This involves identifying how it is possible to reduce or eliminate the problem, e.g. by conducting a BM among a team of experts. In order to undertake improvement actions effectively, it is necessary to define them due to the identified main cause of the problem. This stage is the last stage of the proposed method.

\section{RESULTS}

Testing of the method was carried out on the example of non-metallic inclusions on a product from AMS6415 steel. This incompatibility often was detected by NDT research (magnetic powder method) in one of the production and services enterprises located in Podkarpackie voivodeship. The problem was unequivocal 
identification of the main cause of occurrence of this incompatibility. Mentioned AMS6515 steel is low alloy steel with intended use to produce aviation products, i.e. rods, mechanical pipes, forgings, and wrought materials. According to the first stage of the method, the aim was assumed, i.e. to identify precisely the main cause of non-metallic inclusions on a product from AMS6415 steel. After the second and third stages of the method, a team of experts was selected who identified successively the causes of non-metallic inclusions on the product made of AMS6415 steel. For this purpose, brainstorm (BM) was conducted. All identified causes according to the $5 \mathrm{M}+\mathrm{E}$ rule were grouped and then visualized on a cause and effect diagram (Figure 2).

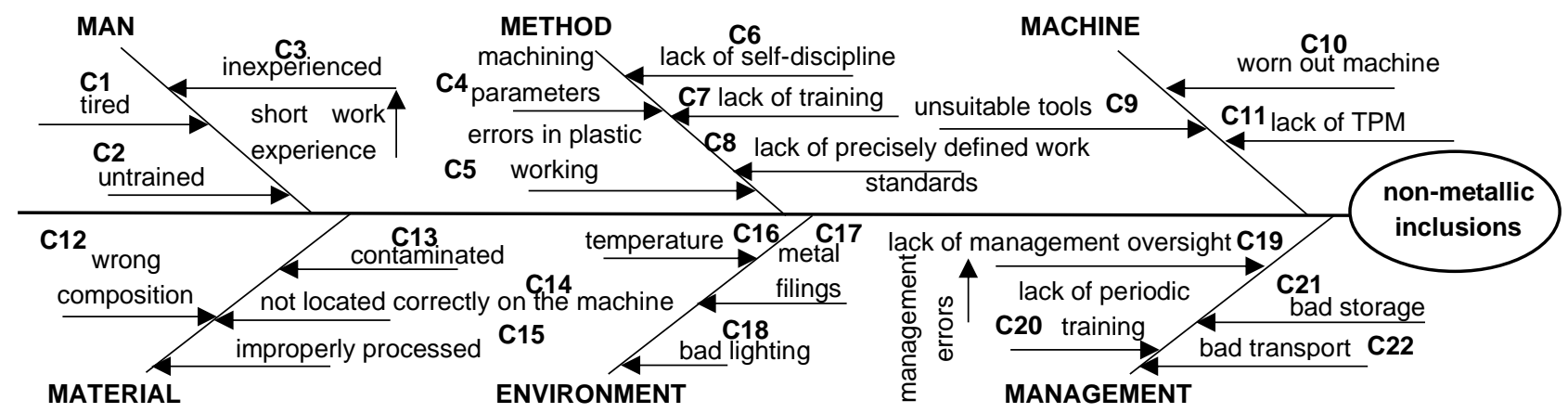

Figure 2 The Ishikawa diagram for incompatibility of non-metallic inclusions of AMS6415 steel

Then, according to the fourth stage of the method, the DEMATEL method was used, to identify the main cause of non-metallic inclusions of AMS6415 steel. The direct interactions of causes were assessed (Table 1a), the structure of the total influence of these causes was determined, and a matrix of the entire interactions of causes was created (Table 1b). As result, the degree of mutual causes was calculated, and the average assessments of all causes in the T matrix was achieved, i.e. $\alpha=0,11$ (Table 1c).

Table $1 \mathrm{~A}$ fragment of the results for the matrix: a) direct interactions, b) entire interactions, c) degree of mutual causes

\begin{tabular}{|c|c|c|c|c|c|}
\hline A & C1 & C2 & C3 &.. & C22 \\
\hline C1 & 0 & 1 & 2 &.. & 3 \\
\hline C2 & 1 & 0 & 4 &.. & 3 \\
\hline C3 & 1 & 2 & 0 &.. & 2 \\
\hline .. &.. &.. &.. &.. &.. \\
\hline C22 & 1 & 1 & 1 &.. & 0 \\
\hline
\end{tabular}

\begin{tabular}{|c|c|c|c|c|c|}
\hline T & C1 & C2 & C3 &.. & C22 \\
\hline C1 & 1.04 & 0.07 & 0.09 &.. & 0.11 \\
\hline C2 & 0.06 & 1.06 & 0.12 &.. & 0.11 \\
\hline C3 & 0.05 & 0.07 & 1.04 &.. & 0.07 \\
\hline .. &.. &.. &.. &.. &.. \\
\hline C22 & 0.04 & 0.04 & 0.04 &.. & 1.02 \\
\hline
\end{tabular}

\begin{tabular}{|c|c|c|c|c|}
\hline $\mathbf{C}$ & $\mathbf{R}_{\mathbf{i}}$ & $\mathbf{C}_{\mathbf{i}}$ & $\mathbf{R}_{\mathbf{i}}+\mathbf{C}_{\mathbf{i}}$ & $\mathbf{R}_{\mathbf{i}}-\mathbf{C}_{\mathbf{i}}$ \\
\hline C1 & 3.32 & 2.05 & 5.37 & 1.27 \\
\hline C2 & 3.36 & 2.30 & 5.65 & 1.06 \\
\hline C3 & 2.56 & 2.34 & 4.89 & 0.22 \\
\hline.. &.. &.. &.. &.. \\
\hline C22 & 1.97 & 2.39 & 4.36 & -0.41 \\
\hline
\end{tabular}

After reducing the matrix $T$ by irrelevant causes of the problem (i.e. values below $\alpha=0.11$ ), a diagram of the mutual influences of the causes of non-metallic inclusions on the product from AMS6415 steel was created (Figure 3).

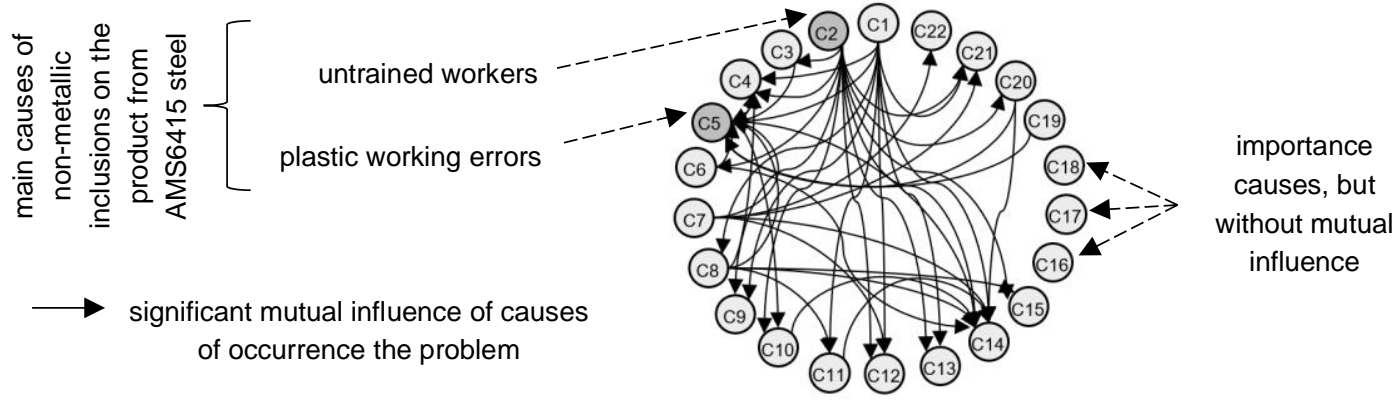

Figure 3 The DEMATEL diagram for causes of non-metallic inclusions of AMS6415 steel 
After analyzing the problem, it has been shown that the main causes of non-metallic inclusions of AMS6415 were untrained workers and plastic working errors. These causes have the maximum number of mutual, important connections, i.e. 14. For that reason, as a part of these main causes, the improvement actions were proposed, i.e.: conducting reminder training for employees, re-examining the forming process and updating work instructions for forming.

\section{DISCUSSION}

The incompatibilities of products are determined by cause and effect connections. Hence, it is necessary to analyze it in an effective way as a part of solving the decision problems. Therefore, the method for solving these types of problems was proposed. The main benefits of the proposed method are:

- $\quad$ categorization and selection of the causes of the problem,

- verifying the mutual influence and relation of causes the problem,

- determining the main cause of the problem,

- a possibility of using the method to complex problems, e.g. incompatibility of product,

- $\quad$ supporting making decision about causes of the problem.

In turn, the disadvantage of the proposed method is a need to assess the dependence, which becomes time-consuming and error-prone for a large group of causes. As a part of future research, it is planned to extend the method about techniques that will reduce uncertainty and imprecision of experts' assessments, i.e. fuzzy numbers.

\section{CONCLUSION}

The support of improvement actions of products is a complex problem and it requires cause and effect analysis. Mainly, it concerns determining causes of occurrence of the incompatibilities of products, which often are identified by popular non-destructive testing (NDT). Therefore, the aim of the article was to propose the method to solve the causes and effects problem as a part of determining the main cause of the problem. The proposed method is a combination of techniques, i.e. brainstorm (BM), Ishikawa diagram (causes and effects) and DEMATEL method. Testing of the method was carried out on the example of non-metallic inclusions on a product from AMS6415 steel. This incompatibility was often detected by NDT research (magnetic powder method) in one of the production and services enterprises located in Podkarpackie voivodeship. Initially, the brainstorm (BM) among a selected team of experts was done, after which the causes of this incompatibility were identified. Then, using the Ishikawa diagram, the all causes were grouped and visualized with rule $5 \mathrm{M}+\mathrm{E}$. Next, the significant influence of all causes of the problem was analysed. The DEMATEL method was used for it. As a result, the two main causes of non-metallic inclusions of AMS6415 steel were determined. These causes were untrained workers and plastic working errors. In the last stage, the improvement actions were proposed, i.e.: conducting reminder training for employees, re-examining the forming process and updating work instructions for forming. It was concluded, that the proposed method has supported the process of cause and effect analysis of incompatibility of the non-metallic inclusions on a product from AMS6415 steel. Therefore, it was considered that the proposed method can be used to verify another kind of incompatibilities of the product, among others from low alloy steel and incompatibilities identified by NDT.

\section{REFERENCES}

[1] ULEWICZ, R., SIWIEC, D., PACANA, A., TUTAK, M., BRODNY, J. Multi-Criteria Method for the Selection of Renewable Energy Sources in the Polish Industrial Sector. Energies. [online]. 2021, vol. 14, p. 2386. Available from: https://doi.org/10.3390/en14092386. 
[2] PACANA, A., SIWIEC, D., BEDNÁROVÁ, L. Method of Choice: A Fluorescent Penetrant Taking into Account Sustainability Criteria. Sustainability. [online]. 2020, vol. 12, 5854. Available from: https://doi.org/10.3390/su12145854.

[3] PACANA, A., SIWIEC, D. BEDNAROVA, L. Analysis of the incompatibility of the product with fluorescent method. Matalurgija. 2019, vol. 58, no. 3-4, pp. 337-340.

[4] ROSSITER, J., LILIEN, G. New "Brainstorming" Principles. Australian Journal of Management. [online]. 1994, vol. 19, no. 1, pp. 61-72. Available from: https://doi.org/10.1177/031289629401900104.

[5] PUTMAN, V., PAULUS, P. Brainstorming, Brainstorming. Rules and Decision Making. Journal of Creative Behavior. 2008, pp. 1-17.

[6] ILIE, G., CIOCOIU, C. N. Application of fishbone diagram to determine the risk of an event with multiple causes. Management research and practice. 2010, vol. 2, no. 1, pp. 1-20.

[7] CIOCCIA, M. The Fishbone diagram to identify, systematize and analyze the sources of general purpose technologies. Journal of Social and Administrative Sciences. 2017, vol. 4, no. 4, pp. 291-303.

[8] LUO, T., WU, C., DUAN, L. (2018). Fishbone diagram and risk matrix analysis method and its application in safety assessment of natural gas spherical tank. Journal of Cleaner Production. [online]. 2018, vol. 174, pp. 296-304. Available from: https://doi.org/10.1016/j.jclepro.2017.10.334.

[9] WAWRZYNEK, Ł. Wykorzystanie metody DEMATEL w budowaniu konkurencyjności. Research papers of Wrocław University of Economics. [online]. 2014, vol. 363, pp. 64-74. Available from: https://doi.org/10.15611/pn.2014.363.06.

[10] DYTCZAK, M., GINDA, G. Miejsce metody DEMATEL w rozwiązywaniu złożonych zadań decyzyjnych. The Wroclaw School of Banking Research Journal. 2015, vol. 15, no. 5, pp. 631-644.

[11] REN L., LUO, C. Questionnaire survey and DEMATEL method approach for analysis the influent factors of chinese scientific Principal Investigators. Int J Clin Exp Med. 2018, vol. 11, no. 2, pp. 848-855.

[12] AMIRI, M. ET AL. Developing a DEMATEL method to prioritize distribution ceners in supply chain. Management Science Letters. 2011, vol. 1, pp. 279-288.

[13] SI, S. et al. DEMATEL Technique: A Systematic Review of the State-of-the-Art Literature on Methodologies and Applications. Mathematical Problems in Engineering. [online]. 2018, vol. 2018, pp. 1-33. Available from: https://doi.org/10.1155/2018/3696457.

[14] LAWLOR, K. B., HORNYAK, M., J. Smart Goals: How The Application Of Smart Goals Can Contribute To Achievement Of Student Learning Outcomes. Developments in Business Simulation and Experiential Learning. 2012, vol. 39, pp. 259-267.

[15] OSTASZ G., et al., Quality management of aluminum pistons with the use of quality control points. Management Systems In Production Engineering. 2020, vol. 28, pp. 29-33

[16] KURPASZEWKICZ, W., ZÓŁTOWSKI, B. (2002). Dobór zespołu ekspertów do diagnozowania stanu maszyn. Diagnostyka. 2002, vol. 26, pp. 94-100. 